\title{
Robot-assisted Salvage Pelvic Lymph Node Dissection
}

National Cancer Institute

\section{Source}

National Cancer Institute. Robot-assisted Salvage Pelvic Lymph Node Dissection. NCI

Thesaurus. Code C161314.

A surgical technique that uses a specially designed robotic system to aid removal of pelvic lymph nodes after failure of initial surgery or other treatment modalities. 